\title{
Characterisation of a collection of Streptococcus pneumoniae isolates from patients suffering from acute exacerbations of chronic bronchitis: In vitro susceptibility to antibiotics and biofilm formation in relation to antibiotic efflux and serotypes/serogroups
}

\author{
Nathalie M. Vandevelde ${ }^{a}$, Paul M. Tulkens ${ }^{a}, *$, Yvan Diaz Iglesias ${ }^{a}$, Jan Verhaegen ${ }^{\mathrm{b}}$, \\ Hector Rodriguez-Villalobos ${ }^{\mathrm{c}}$, Ivan Philippart ${ }^{\mathrm{d}}$, Julie Cadrobbi ${ }^{\mathrm{e}}$, Nathalie Coppens ${ }^{\mathrm{f}}$, \\ An Boel ${ }^{\mathrm{g}}$, Kristien Van Vaerenbergh ${ }^{\mathrm{g}}$, Hugo Francart ${ }^{\mathrm{h}}$, Raymond Vanhoof ${ }^{\mathrm{i}}$, \\ Giuseppe Liistro $^{\mathrm{j}}$, Paul Jordens ${ }^{\mathrm{k}}$, Jean-Paul d'Odemont ${ }^{\mathrm{l}}$, Yvan Valcke ${ }^{\mathrm{m}}$, \\ Franck Verschuren $^{\mathrm{n}}$, Françoise Van Bambeke ${ }^{\mathrm{a}}$ \\ a Pharmacologie cellulaire et moléculaire E' Centre de Pharmacie Clinique, Louvain Drug Research Institute, Université catholique de Louvain, Brussels, \\ Belgium \\ ${ }^{\mathrm{b}}$ Laboratorium microbiologie, Universitair Ziekenhuis Gasthuisberg, Leuven, Belgium \\ ${ }^{\mathrm{c}}$ Laboratoire de microbiologie, Cliniques universitaires St Luc, Brussels, Belgium \\ d Laboratoire de microbiologie, Centre hospitalier régional Mons-Warquignies, Warquignies, Belgium \\ e Laboratoire de microbiologie, Clinique et Maternité Ste Elisabeth, Namur, Belgium \\ ${ }^{\mathrm{f}}$ Service de pneumologie, Clinique et Maternité Ste Elisabeth, Namur, Belgium \\ ${ }^{\mathrm{g}}$ Laboratorium microbiologie, Onze Lieve Vrouw Ziekenhuis, Aalst, Belgium \\ ${ }^{\mathrm{h}}$ Laboratorium microbiologie, Algemeen Ziekenhuis Nikolaas, St Niklaas, Belgium \\ i Institut Scientifique de Santé Publique, Brussels, Belgium \\ j Service de pneumologie, Cliniques universitaires St Luc, Brussels, Belgium \\ ${ }^{\mathrm{k}}$ Pneumologie, Onze Lieve Vrouw Ziekenhuis, Aalst, Belgium \\ ${ }^{1}$ Service de pneumologie, Centre hospitalier régional Mons-Warquignies, Warquignies, Belgium \\ $\mathrm{m}$ Longziekten en allergieën, Algemeen Ziekenhuis Nikolaas, St Niklaas, Belgium \\ ${ }^{n}$ Service des Urgences, Cliniques universitaires Saint-Luc, Brussels, Belgium
}

\section{A R T I C L E I N F O}

\section{Article history:}

Received 10 March 2014

Accepted 18 May 2014

\section{Keywords:}

Acute exacerbations of chronic bronchitis (AECB)

Streptococcus pneumoniae

Susceptibility

Serotype

Biofilm

Efflux

\begin{abstract}
A B S T R A C T
The correlation between Streptococcus pneumoniae serotypes, biofilm production, antibiotic susceptibility and drug efflux in isolates from patients suffering from acute exacerbations of chronic bronchitis (AECB) remains largely unexplored. Using 101 isolates collected from AECB patients for whom partial $(n=51)$ or full $(n=50)$ medical details were available, we determined serotypes (ST)/serogroups (SG) (Quellung reaction), antibiotic susceptibility patterns [MIC (microdilution) using EUCAST and CLSI criteria] and ability to produce biofilm in vitro (10-day model; crystal violet staining). The majority of patients were $55-75$ years old and $<5 \%$ were vaccinated against S. pneumoniae. Moreover, $54 \%$ showed high severity scores (GOLD 3-4), and comorbidities were frequent including hypertension (60\%), cancer (24\%) and diabetes (20\%). Alcohol and/or tobacco dependence was $>30 \%$. Isolates of SG6-11-15-23, known for large biofilm production and causing chronic infections, were the most prevalent $(>15 \%$ each), but other isolates also produced biofilm (SG9-18-22-27 and ST8-20 being most productive), except SG7, SG29 and ST5 ( $<2 \%$ of isolates each). Resistance (EUCAST breakpoints) was 8-13\% for amoxicillin and cefuroxime, 35-39\% for macrolides, $2-8 \%$ for fluoroquinolones and $2 \%$ for telithromycin. ST19A isolates showed resistance to all antibiotics, ST14 to all except moxifloxacin, and SG9 and SG19 to all except telithromycin, moxifloxacin and ceftriaxone (SG19 only). Solithromycin and telithromycin MICs were similar. No correlation was observed between biofilm production and MIC or efflux (macrolides, fluoroquinolones). S. pneumoniae serotyping may improve AECB treatment by avoiding antibiotics with predictable low activity, but it is not predictive of biofilm production.
\end{abstract}

(c) 2014 Elsevier B.V. and the International Society of Chemotherapy. All rights reserved.

\footnotetext{
* Corresponding author. Tel.: +32 27647371.

E-mail address: tulkens@facm.ucl.ac.be (P.M. Tulkens).
} 


\section{Introduction}

Chronic obstructive pulmonary disease (COPD) remains one of the major causes of morbidity and mortality worldwide, occupying the fourth place for death since 2000 and predicted to reach third place in 2020 [1,2]. At increasingly closer intervals, COPD patients suffer from acute exacerbations of chronic bronchitis (AECB), which contribute to alteration of their respiratory function. These episodes are characterised by increased dyspnoea, coughing and sputum production, being evidence of infection of the airways [3]. Bacterial pathogens are found in $50-80 \%$ of cases of AECB [4], with Streptococcus pneumoniae being one of the dominant species $[1,4]$. Recurrence of infections associated with bacterial persistence results in frequent antibiotic courses. This favours the emergence of multiresistance of S. pneumoniae [5] through a variety of non-mutually exclusive mechanisms such as alterations in the antibiotic targets for $\beta$-lactams and macrolides as well as overexpression of efflux pumps for macrolides and fluoroquinolones [6]. Biofilm formation also favours the persistence of S. pneumoniae in the airways [7]. Up to $80 \%$ of chronic infections involve pneumococcal growth and survival within biofilms [8,9], in direct relation to the ability of this organism to colonise the nasopharynx [10], which may be dependent on its serotype (ST)/serogroup (SG) [11]. Whilst more than 90 distinct STs have been described for S. pneumoniae [12], few studies have attempted to examine what correlations exist between ST and/or SG and the ability to form thick biofilms in clinical isolates from patients with COPD [1]. Moreover, none of these studies have extended the correlations to key properties of the isolates such as their susceptibility to commonly recommended antibiotics and the expression of efflux transporters. Since efflux is critical in other bacteria for liberating quorum-sensing signalling molecules involved in biofilm formation [13], we also investigated the relationship between the ability of $S$. pneumoniae to form biofilm and the presence of phenotypic efflux for macrolides and ciprofloxacin.

In the present report, we show (i) that the susceptibility of $S$. pneumoniae isolates from COPD patients to $\beta$-lactams and fluoroquinolones is lower than that seen for patients with a confirmed diagnosis of bacterial community-acquired pneumonia (CAP) [14], (ii) that most of these isolates produce large amounts of biofilm irrespective of their ST/SG and (iii) that there is no correlation between the ability for biofilm formation in vitro and susceptibility to antibiotics or efflux towards macrolides or fluoroquinolones amongst the isolates investigated.

\section{Materials and methods}

\subsection{General outline of the clinical study, patient selection and medical data acquisition}

A first series of isolates consisted of 48 non-duplicate $S$. pneumoniae strains obtained between March 2006 and December 2008 from patients with a declared diagnosis of AECB and was assembled at the Belgian Scientific Institute of Public Health (Brussels, Belgium). Samples from this collection were equally distributed between the Belgian provinces in relation to their population. The second series of isolates consisted of 53 non-duplicate strains obtained in a prospective fashion between November 2010 and May 2013. For this purpose, five hospitals (one teaching and four non-teaching) were contacted and asked to enrol patients with a suspicion of AECB whether self-referred or referred by a general practitioner. Patients were enrolled upon obtaining a sample of sputum from the lower respiratory tract fulfilling the microbiological interpretive criteria of an acceptable specimen for culture [abundance of white blood cells (WBCs), few epithelial cells at low-power magnification, and $\geq 10-25$ WBCs with no epithelial cells under $1000 \times$ magnification]. Only patients with samples yielding a positive culture for $S$. pneumoniae and with a confirmed diagnosis of AECB based on Anthonisen's criteria [3] were retained. For 50 of these patients, the whole medical data could be collected and was anonymised. Patients were stratified based on the severity scores (1-4 classification of the 2013 edition of the Global Initiative for Chronic Obstructive Lung Disease [GOLD] report [15]), sex, age, length of hospitalisation, geographical location, co-morbidities, smoking habit and therapeutic treatment at admission. Smoking habits were obtained from the patient's declaration. Tobacco usage was converted into 'pack $\times$ year' units by multiplying the number of packs smoked per day by the number of years as a smoker (using a threshold of $>20$ for increased risk of tobacco-related cancer [16]).

\subsection{Bacterial strains and growth conditions}

After identification in each clinical laboratory, strains were stored at $-80^{\circ} \mathrm{C}$ for transfer to a central laboratory until used for our experiments. Confirmation of identification was made by growth inhibition by optochin (Oxoid Ltd., Basingstoke, UK), and serotyping was performed as previously described [17]. Streptococcus pneumoniae ATCC 49619 strain (capsulated ST19F [18]) was used for quality control in each set of experiments. All strains were grown on Mueller-Hinton blood agar plates supplemented with 5\% defibrinated horse blood incubated at $37^{\circ} \mathrm{C}$ in a $5 \% \mathrm{CO}_{2}$ atmosphere.

\subsection{Susceptibility testing}

Minimum inhibitory concentrations (MICs) were determined by microdilution following the guidelines of the Clinical and Laboratory Standards Institute (CLSI) [19]. MICs were read after 18-24 h of incubation at $37^{\circ} \mathrm{C}$. To improve accuracy, concentrations at half a value of each standard geometric progression were used as previously described [14] over the whole concentration range investigated. MICs were categorised as susceptible, intermediate or resistant according to the CLSI and European Committee on Antimicrobial Susceptibility Testing (EUCAST) interpretive breakpoints $[19,20]$.

\subsection{Assessment of efflux phenotypes}

The efflux resistance phenotype to macrolides was determined by examining the dissociation of susceptibilities between clarithromycin and clindamycin (substrate and non-substrate of the macrolide efflux transporters, respectively [14]). Efflux of fluoroquinolones was detected by a decrease in the MIC upon addition of reserpine $(10 \mathrm{mg} / \mathrm{L})$, an inhibitor of both PatA/B and PmrA fluoroquinolone efflux transporters in S. pneumoniae [14].

\subsection{In vitro development of biofilms and determination of biofilm mass}

Ninety-six well plates (European cat. no. 734-2327; VWR, Radnor, PA) were used as the support for biofilm growth. In each well, $25 \mu \mathrm{L}$ of bacterial culture [optical density at $620 \mathrm{~nm}\left(\mathrm{OD}_{620}\right)=0.1$ ] were added to $175 \mu \mathrm{L}$ of cation-adjusted Mueller-Hinton broth supplemented with 5\% lysed horse blood (Oxoid Ltd.) and 2\% glucose as previously described [18]. Biofilm development was obtained by incubation for $2-10$ days at $37{ }^{\circ} \mathrm{C}$ in a $5 \% \mathrm{CO}_{2}$ atmosphere with medium replacement every $48 \mathrm{~h}$. Biofilms examined after 2 days or 10 days are referred to as young and mature biofilms, respectively. Biofilm mass was evaluated by staining with crystal violet followed by measuring the absorbance exactly as previously described [18]. Each isolate was tested twice at different dates, with each assay using three to six measures. The mean coefficient of 
variation of the assay was $12.3 \%$ (extremes, $0.01-33.1$ ). Data of all determinations for each isolate were pooled, and STs belonging to a given SG were regrouped after observing no significant differences in their capacity to form biofilm.

\subsection{Antibiotics and other products}

Amoxicillin, cefuroxime and ceftriaxone were obtained as the corresponding branded product for human parenteral use complying with the prescriptions of the European Pharmacopoeia ( $>90 \%$ purity) and distributed for clinical use in Belgium as, respectively, Clamoxyl ${ }^{\circledR}$ and Zinacef ${ }^{\circledR}$ by GlaxoSmithKline s.a./n.v. (Genval, Belgium) and Rocephin ${ }^{\circledR}$ by Roche s.a./n.v. (Brussels, Belgium). Clindamycin hydrochloride (potency 92.1\%) was obtained from Sigma-Aldrich (St Louis, MO). Clarithromycin and azithromycin (potencies 100\%) were from Teva Pharmaceutical Industries (Petah Tikva, Israel); telithromycin (potency 100\%) and levofloxacin hemihydrate (potency 97.5\%) were from SanofiAventis Deutschland GmbH (Frankfurt, Germany); solithromycin (potency 100\%) was from Cempra Pharmaceuticals (Chapel Hill, NC); and moxifloxacin chlorhydrate (potency 90.9\%) was from Bayer AG (Leverkusen, Germany). Reserpine was obtained from Fluka (Buchs, Switzerland). All other products were obtained from Sigma-Aldrich or E. Merck AG (Darmstadt, Germany).

\subsection{Statistical analyses}

Unpaired t-test, one-way analysis of variance (ANOVA) and contingency tables were made with GraphPad Prism ${ }^{\circledR} 4.02$ and GraphPad InStat ${ }^{\circledR} 3.10$ (GraphPad Software Inc., San Diego, CA) and recursive partitioning analyses with JMP ${ }^{\circledR}$ 10.0.2 (SAS Institute Inc., Cary, NC).

\section{Results}

\subsection{Main characteristics of patients}

Table 1 shows the demographic characteristics of the whole patient population. Most patients were 55-75 years of age. For samples prospectively collected, two hospitals provided a number of samples markedly above the average (in proportion to their bed capacity) owing to their location in or proximity to industrial areas. Most of these patients were living at home prior to hospitalisation and were smokers (more than three-quarters currently active or former deep smokers). Most patients remained hospitalised after reporting. The severity of their disease was equally distributed between low ( 1 or 2 ) and high ( 3 or 4 ) GOLD scores. Co-morbidity percentages ranged from $20 \%$ to $30 \%$ for diabetes, cancer and alcoholism, and to $60 \%$ for arterial hypertension.

\subsection{Correlations between demographic, clinical and pharmaceutical parameters}

Associations between demographic factors, severity of disease, co-morbidities and drug usage were examined in 50 patients for whom full medical records were available. Table 2 shows that the length of hospitalisation was clearly correlated with the severity of disease and with tobacco dependence. Older patients had a more severe obstructive syndrome and were more often hypertensive, were poorly vaccinated and showed less incidence of alcoholism.

\subsection{Serotype/serogroup analyses}

Serotyping was performed on all isolates $(n=101)$. Fig. 1 A shows the distribution of STs/SGs amongst the two successive series of isolates (2006-2008 and 2010-2013) stratified by level of coverage (partial or total) with PCV7 [7-valent pneumococcal conjugate vaccine (Prevenar ${ }^{\circledR}$; Wyeth)] and PPV-23 [23-valent pneumococcal polysaccharide vaccine (Pneumo $23^{\circledR}$; Sanofi-Pasteur MSD)] (the two vaccines in usage at the time during which most isolates were obtained), and for each of these groups by frequency. Whilst there were some changes in ST/SG frequencies between the two series of isolates, SG6 and SG23 were the most prevalent throughout. The second series of isolates also contained a large proportion of SG11 and SG15 strains. There was no marked heterogeneity in ST/SG between the contributing regions (based on patients' living place records; see Supplementary Fig. S1). Globally speaking, only $5 \%$ of patients hospitalised during the 2010-2013 period had been vaccinated but most isolates were actually from a ST/SG not fully

Table 1

Patients' demographic characteristics and environmental and medical conditions.

\begin{tabular}{|c|c|c|c|c|c|c|}
\hline Age and no. enrolled & Mean \pm S.D. (years) & $<55$ years & $\geq 55$ to $<65$ years & $\geq 65$ to $<75$ years & $\geq 75$ to $<85$ years & $\geq 85$ years \\
\hline & $67.2 \pm 12.7$ & $11(10.9 \%)$ & $33(32.7 \%)$ & $30(29.7 \%)$ & $23(22.8 \%)$ & $4(4.0 \%)$ \\
\hline
\end{tabular}

2. Prospectively assembled population (2010-2013) $(n=53)$

\begin{tabular}{|c|c|c|c|c|c|c|}
\hline Hospital & A & B & $\mathrm{C}$ & $\mathrm{D}$ & $\mathrm{E}$ & Total \\
\hline No. enrolled & 8 & 8 & 3 & 20 & 14 & 53 \\
\hline$\%$ of capacity ${ }^{a}$ & 0.8 & 0.95 & 0.36 & 3.6 & 4.7 & $2.1 \pm 1.94($ mean \pm S.D. $)$ \\
\hline
\end{tabular}

3. Patients from prospectively assembled population and with available medical data $(n=50)$

\begin{tabular}{|c|c|c|c|}
\hline $\begin{array}{l}\text { General and } \\
\text { environmental } \\
\text { conditions }\end{array}$ & $\operatorname{Sex}(\% \mathrm{M} / \mathrm{F}): 74 / 26$ & $\begin{array}{l}\text { Living place (\% home/nursing } \\
\text { home/psychiatric institution): } 88 / 4 / 8\end{array}$ & $\begin{array}{l}\text { Smoking habits }{ }^{\mathrm{b}}(\% \\
\text { active/former/non-smoker/unknown): 56/28/6/10 }\end{array}$ \\
\hline Disease severity & \multicolumn{2}{|c|}{ Hospitalisation (\% yes/no): $80 / 20$} & GOLD score (\% 1 or $2 / 3$ or 4 ): $46 / 54$ \\
\hline Co-morbidities & Hypertension $^{c}$ (\%): 60 & Diabetes $^{\mathrm{d}}(\%): 20$ & $\operatorname{Alcoholism}^{\mathrm{f}}(\%): 30$ \\
\hline
\end{tabular}

S.D., standard deviation; GOLD, Global Initiative for Chronic Obstructive Lung Disease [15].

a No. of enrolled patients/no. of beds in the hospital $\times 100$.

b According to patient's declaration.

c Systolic blood pressure $>120 \mathrm{mmHg}$.

d Fasting glycaemia $>1.26 \mathrm{~g} / \mathrm{L}$.

e Tissue biopsies and/or chest radiographs.

${ }^{\mathrm{f}}$ According to patient's declaration, evidence at admission (inebriated condition) or presence of alcoholic cirrhosis. 
Table 2

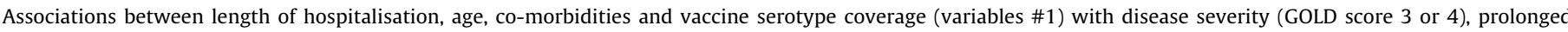

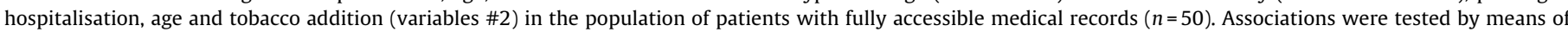

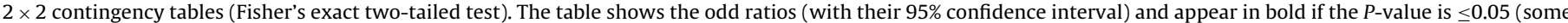
associations with a $P$-value between 0.05 and 0.1 are shown in italic if considered potentially medically important).

\begin{tabular}{|c|c|c|c|c|}
\hline \multirow[t]{2}{*}{ Variable \#1 } & \multicolumn{4}{|l|}{ Variable \# 2} \\
\hline & Disease severity $^{\mathrm{a}}$ & Hospitalisation $>10$ days & Age $>65$ years & Tobacco addiction ${ }^{\mathrm{b}}$ \\
\hline Hospitalisation $>10$ days & $2.987(1.242-7.182), P<0.05$ & & $1.289(0.571-2.91), \mathrm{ns}$ & $3.201(0.9928-10.322), P<0.05$ \\
\hline Age $>65$ years & $2.963(1.296-6.772), P<0.05$ & $1.289(0.571-2.91), \mathrm{ns}$ & & $0.408(0.16-1.039), P=0.0761$ \\
\hline High blood pressure ${ }^{c}$ & $0.641(0.284-1.451), \mathrm{ns}$ & 0.835 (0.369-1.889), ns & 3.947 (1.688-9.233), $P<0.01$ & 2.545 (0.9643-6.719), $P=0.07$ \\
\hline Alcoholism $^{\mathrm{d}}$ & $0.424(0.180-1.000), P=0.0541$ & $1.128(0.469-2.712), \mathrm{ns}$ & $0.087(0.031-0.246), P<0.0001$ & $1.071(0.389-2.952), \mathrm{ns}$ \\
\hline Cancer $^{\mathrm{e}}$ & $2.7(0.966-7.548), P=0.06$ & 0.767 (0.292-2.013), ns & $2.700(0.966-7.548), P=0.06$ & $0.353(0.117-1.058), P=0.07$ \\
\hline Vaccine coverage $^{f}$ & $1.250(0.416-3.758), \mathrm{ns}$ & 0.490 (0.146-1.649), ns & $0.185(0.0549-0.625), P<0.01$ & $1.071(0.316-3.634), \mathrm{ns}$ \\
\hline
\end{tabular}

a Global Initiative for Chronic Obstructive Lung Disease (GOLD) score 3 or 4 [15].

b $>20$ 'pack $\times$ years'.

c Systolic blood pressure $>120 \mathrm{mmHg}$

d According to patient declarations, evidence at admission (inebriated condition) or presence of alcoholic cirrhosis.

e Tissue biopsies and/or chest radiographs.

${ }^{f}$ Vaccine PCV13 [13-valent pneumococcal conjugate vaccine (Prevenar 13 ${ }^{\circledR}$; Wyeth)] covers serotypes 1, 3, 4, 5, 6A, 6B, 7F, 9V, 14, 18C, 19A, 19F and 23F; and vaccine

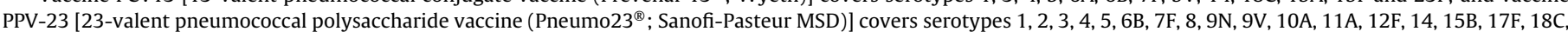
19A, 19F, 20, 22F, 23F and 33F.

covered by the two vaccines examined (adding the STs covered by the PCV13 did not much change this pattern). Fig. 1B shows the STs/SGs of all isolates when stratified as a function of their ability reported in the literature of being (i) high biofilm producers and causing chronic infections [1,9], (ii) low biofilm producers and causing acute infections $[9,14,21]$ or (iii) with undescribed ability for these characteristics. Approximately one-half of the isolates were found in the first group.

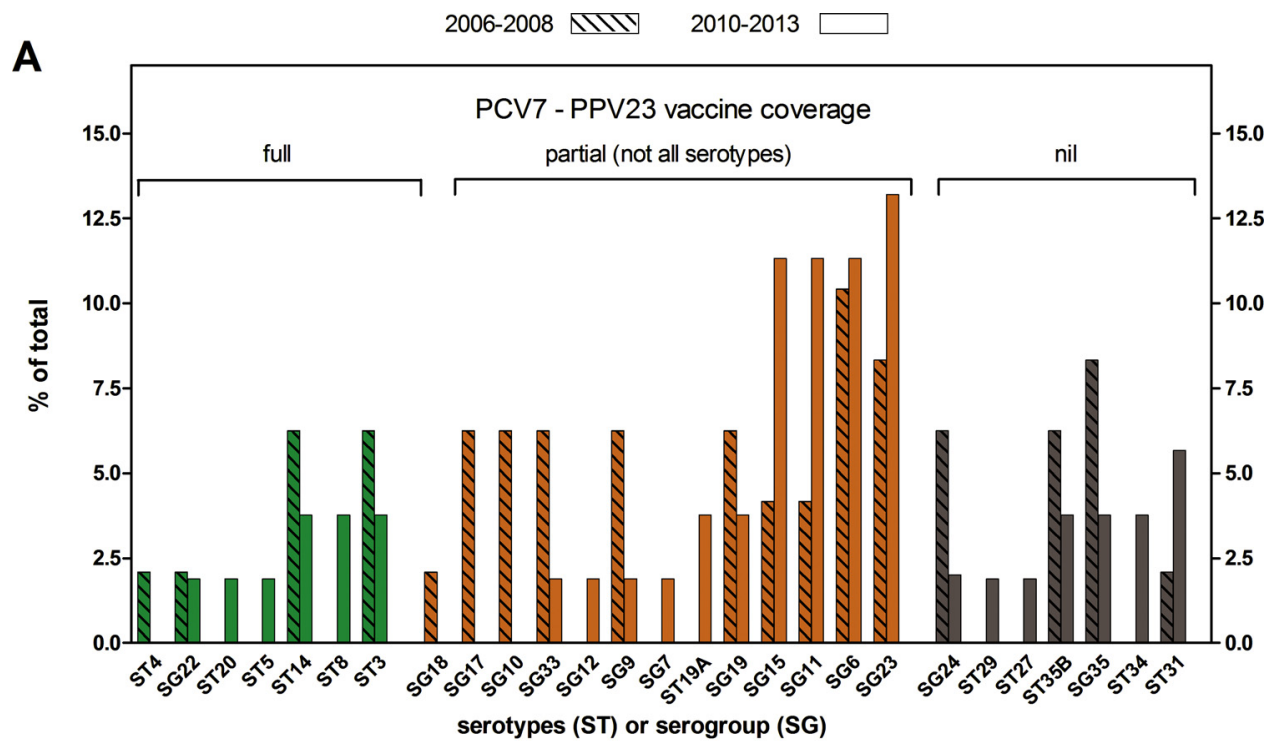

B
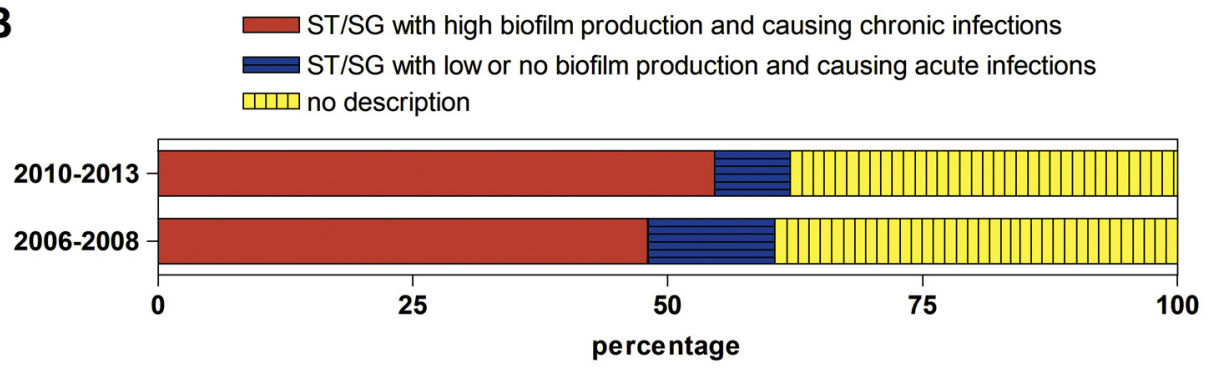

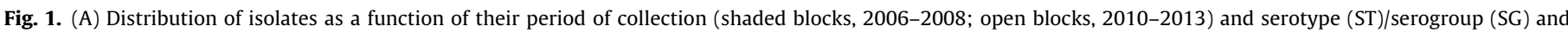

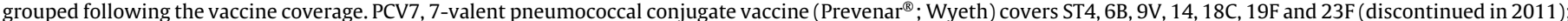

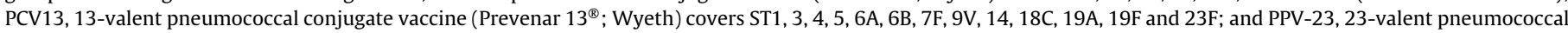

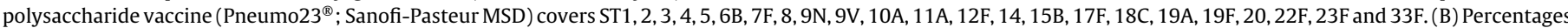

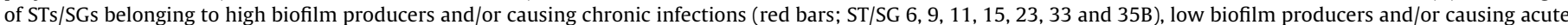

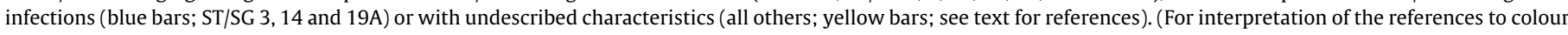
in this figure legend, the reader is referred to the web version of this article.) 

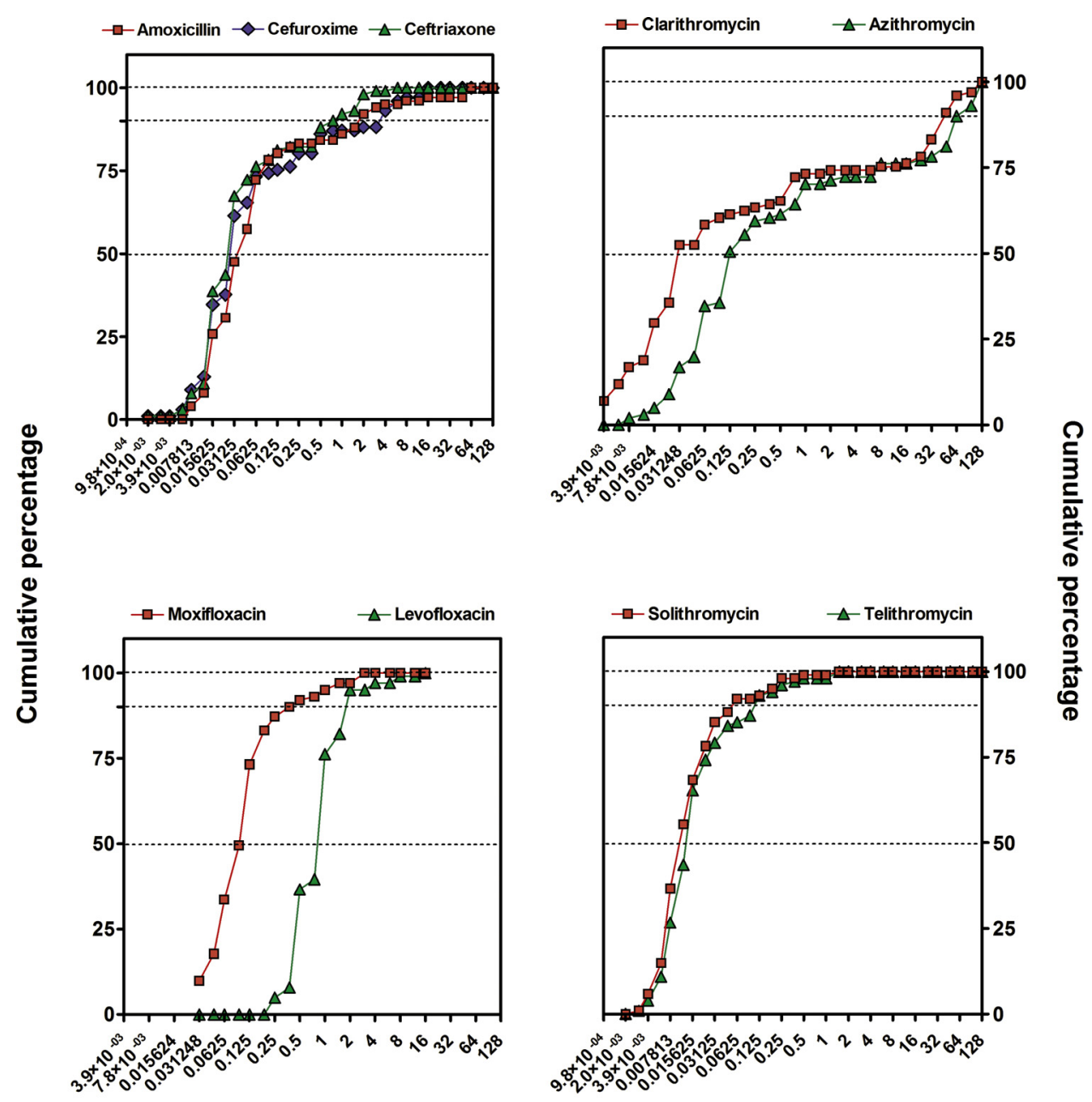

\section{Minimum inhibitory concentrations (mg/L)}

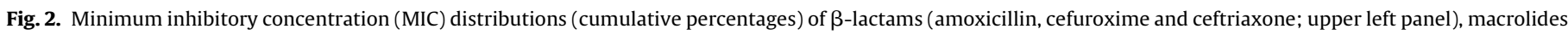

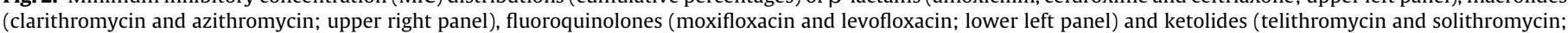

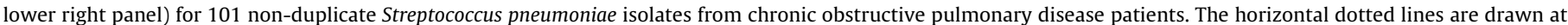
values corresponding to the $\mathrm{MIC}_{50}$, $\mathrm{MIC}_{90}$ and $\mathrm{MIC}_{100}$ (MICs required to inhibit $50 \%, 90 \%$ and $100 \%$ of the isolates, respectively).

\subsection{Characterisation of the in vitro susceptibility to antibiotics and correlation with the severity of disease and serotypes/serogroups}

All of the strains were characterised for their susceptibility to antibiotics focusing on (i) drugs commonly recommended for the ambulatory treatment of bacterial exacerbations of chronic bronchitis in Belgium at the time of the study (amoxicillin, cefuroxime [administered as its axetil prodrug] and moxifloxacin [22]) and (ii) ceftriaxone (an often prescribed $\beta$-lactam in hospitals), clarithromycin and azithromycin (often used in combination with a $\beta$-lactam) and levofloxacin (as an alternative antipneumococcal fluoroquinolone). We also added two ketolides [telithromycin (approved in Europe for the treatment of exacerbations of chronic bronchitis) and solithromycin (still investigational)] because of their reported good activity against $S$. pneumoniae resistant to macrolides [23], and tested clindamycin and ciprofloxacin for efflux diagnostic purposes. Cumulative MIC distributions are shown in Fig. 2 (see also Supplementary Fig. S2). $\mathrm{MIC}_{50}$ and $\mathrm{MIC}_{90}$ values (MIC required to inhibit $50 \%$ and $90 \%$ of the isolates, respectively) and analysis of the MIC profiles according both to EUCAST and CLSI interpretive criteria are presented in Table 3 for all strains and for each collection individually. There were no significant differences in susceptibilities between the two strain collections. Moreover, largely similar distributions were observed for all three $\beta$-lactams except in the zones corresponding to their clinical breakpoints, with $6-8 \%$ of all isolates falling into the intermediate category for the three drugs and $8-13 \%$ in the fully resistant category for amoxicillin and cefuroxime (using, for the latter, the interpretive criteria set for its oral form), but only $1 \%$ for ceftriaxone, based on EUCAST interpretive criteria (using CLSI interpretive criteria essentially resulted in having no or only one isolate in the intermediate category). For macrolides, isolates within the first half of the cumulative distribution were globally more susceptible to clarithromycin than azithromycin. The difference, however, largely disappeared for isolates with higher MICs. Resistance rates to clarithromycin and azithromycin reached $28 \%$ and $39 \%$ based on EUCAST interpretive criteria, and $27 \%$ and $29 \%$ based on CLSI interpretive criteria. Isolates categorised as intermediate were rare $(<10 \%)$. The cumulative clindamycin MIC distribution was essentially similar to that of azithromycin, indicating that most of the strains categorised as resistant to this macrolide were of the $\mathrm{MLS}_{\mathrm{B}}$ type. For fluoroquinolones, moxifloxacin was systematically more active than levofloxacin, but due to the lower breakpoint set by EUCAST for moxifloxacin, more strains ( $8 \%$ ) were categorised as being resistant compared with levofloxacin (3\%). No meaningful difference with respect to susceptibility was seen if using CLSI breakpoints. For ciprofloxacin, the majority of isolates had a MIC in the intermediate 
Table 3

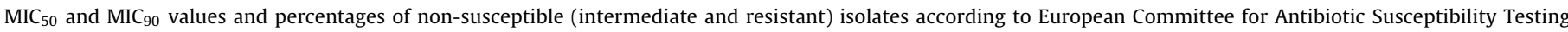
(EUCAST) and Clinical and Laboratory Standards Institute (CLSI) interpretive criteria.

\begin{tabular}{|c|c|c|c|c|c|c|c|}
\hline \multirow[t]{3}{*}{ Antibiotic } & \multirow[t]{3}{*}{ Strains collection } & \multicolumn{2}{|c|}{$\mathrm{MIC}(\mathrm{mg} / \mathrm{L})$} & \multicolumn{4}{|c|}{ \% Susceptibility according to: } \\
\hline & & \multirow[t]{2}{*}{$\mathrm{MIC}_{50}$} & \multirow[t]{2}{*}{$\mathrm{MIC}_{90}$} & \multicolumn{2}{|l|}{ EUCAST [20] } & \multicolumn{2}{|l|}{ CLSI [19] } \\
\hline & & & & $\begin{array}{l}\text { Breakpoint } \\
(\mathrm{S} / \mathrm{R})(\mathrm{mg} / \mathrm{L})\end{array}$ & $\% \mathrm{I} / \mathrm{R}$ & $\begin{array}{l}\text { Breakpoint } \\
(\mathrm{S} / \mathrm{R})(\mathrm{mg} / \mathrm{L})\end{array}$ & $\% \mathrm{I} / \mathrm{R}$ \\
\hline Amoxicillin & $\begin{array}{l}\text { Global } \\
2006-2008 \\
2010-2013\end{array}$ & $\begin{array}{l}0.046875 \\
0.02344 \\
0.06250\end{array}$ & $\begin{array}{l}2 \\
1.5 \\
4\end{array}$ & $\leq 0.5 />2$ & $\begin{array}{l}8 / 8 \\
10 / 4 \\
6 / 11\end{array}$ & $\leq 2 / \geq 8$ & $\begin{array}{l}1 / 4 \\
0 / 0 \\
2 / 9.4\end{array}$ \\
\hline Cefuroxime & $\begin{array}{l}\text { Global } \\
2006-2008 \\
2010-2013\end{array}$ & $\begin{array}{l}0.03125 \\
0.03125 \\
0.01563\end{array}$ & $\begin{array}{l}4 \\
4 \\
4\end{array}$ & $\leq 0.25 />0.5^{a}$ & $\begin{array}{l}6 / 13 \\
6.3 / 14.6 \\
5.7 / 11.3\end{array}$ & $\leq 1 / \geq 4^{a}$ & $\begin{array}{l}1 / 7 \\
2 / 8.4 \\
0 / 5.7\end{array}$ \\
\hline Ceftriaxone & $\begin{array}{l}\text { Global } \\
2006-2008 \\
2010-2013\end{array}$ & $\begin{array}{l}0.03125 \\
0.03125 \\
0.01563\end{array}$ & $\begin{array}{l}0.75 \\
2 \\
0.5\end{array}$ & $\leq 0.5 />2$ & $\begin{array}{l}8 / 1 \\
10.4 / 2 \\
5.7 / 0\end{array}$ & $\leq 2 / \geq 4$ & $\begin{array}{l}0 / 1 \\
0 / 2 \\
0 / 0\end{array}$ \\
\hline Clarithromycin & $\begin{array}{l}\text { Global } \\
2006-2008 \\
2010-2013\end{array}$ & $\begin{array}{l}0.03125 \\
0.03125 \\
0.03125\end{array}$ & $\begin{array}{l}48 \\
48 \\
64\end{array}$ & $\leq 0.25 />0.5$ & $\begin{array}{l}1 / 27.7 \\
0 / 31.2 \\
2 / 24.5\end{array}$ & $\leq 0.25 / \geq 1$ & $\begin{array}{l}7.9 / 26.7 \\
0 / 30.2 \\
15.1 / 22.7\end{array}$ \\
\hline Azithromycin & $\begin{array}{l}\text { Global } \\
2006-2008 \\
2010-2013\end{array}$ & $\begin{array}{l}0.125 \\
0.125 \\
0.250\end{array}$ & $\begin{array}{r}64 \\
64 \\
128\end{array}$ & $\leq 0.25 />0.5$ & $\begin{array}{l}1 / 38.6 \\
0 / 31.2 \\
0 / 39.6\end{array}$ & $\leq 0.5 / \geq 2$ & $\begin{array}{l}6 / 28.7 \\
0 / 31.2 \\
11.3 / 26.4\end{array}$ \\
\hline Clindamycin $^{\mathrm{b}}$ & $\begin{array}{l}\text { Global } \\
2006-2008 \\
2010-2013\end{array}$ & $\begin{array}{l}0.0625 \\
0.046875 \\
0.0625\end{array}$ & $\begin{array}{l}32 \\
16 \\
48\end{array}$ & $\leq 0.5 />0.5$ & $\begin{array}{l}0 / 35.7 \\
0 / 27 \\
0 / 43.4\end{array}$ & NA & $\begin{array}{l}\text { NA } \\
\text { NA } \\
\text { NA }\end{array}$ \\
\hline Telithromycin & $\begin{array}{l}\text { Global } \\
2006-2008 \\
2010-2013\end{array}$ & $\begin{array}{l}0.015625 \\
0.015625 \\
0.015625\end{array}$ & $\begin{array}{l}0.125 \\
0.0625 \\
0.125\end{array}$ & $\leq 0.25 />0.5$ & $\begin{array}{l}1 / 2 \\
0 / 2 \\
2 / 2\end{array}$ & $\leq 1 / \geq 4$ & $\begin{array}{l}0 / 0 \\
0 / 0 \\
0 / 0\end{array}$ \\
\hline Solithromycin & $\begin{array}{l}\text { Global } \\
2006-2008 \\
2010-2013\end{array}$ & $\begin{array}{l}0.01172 \\
0.01172 \\
0.00781\end{array}$ & $\begin{array}{l}0.0625 \\
0.046875 \\
0.0625\end{array}$ & NA & $\begin{array}{l}\text { NA } \\
\text { NA } \\
\text { NA }\end{array}$ & NA & $\begin{array}{l}\text { NA } \\
\text { NA } \\
\text { NA }\end{array}$ \\
\hline Moxifloxacin & $\begin{array}{l}\text { Global } \\
2006-2008 \\
2010-2013\end{array}$ & $\begin{array}{l}0.125 \\
0.125 \\
0.09375\end{array}$ & $\begin{array}{l}0.375 \\
0.5 \\
0.375\end{array}$ & $\leq 0.5 />0.5$ & $\begin{array}{l}0 / 8 \\
0 / 6.3 \\
0 / 9.4\end{array}$ & $\leq 1 / \geq 4$ & $\begin{array}{l}3 / 0 \\
2 / 0 \\
4 / 0\end{array}$ \\
\hline Levofloxacin & $\begin{array}{l}\text { Global } \\
2006-2008 \\
2010-2013\end{array}$ & $\begin{array}{l}1 \\
1 \\
0.75\end{array}$ & $\begin{array}{l}2 \\
2 \\
1.5\end{array}$ & $\leq 2 />2$ & $\begin{array}{l}0 / 3 \\
0 / 2 \\
0 / 4\end{array}$ & $\leq 2 / \geq 8$ & $\begin{array}{l}2 / 1 \\
0 / 0 \\
3.8 / 2\end{array}$ \\
\hline Ciprofloxacin $^{\mathrm{b}}$ & $\begin{array}{l}\text { Global } \\
2006-2008 \\
2010-2013\end{array}$ & $\begin{array}{l}1 \\
1 \\
1\end{array}$ & $\begin{array}{l}4 \\
4 \\
4\end{array}$ & $\leq 0.125 />2$ & $\begin{array}{l}82.2 / 13.8 \\
87.5 / 10.4 \\
77.4 / 17\end{array}$ & NA & $\begin{array}{l}\text { NA } \\
\text { NA } \\
\text { NA }\end{array}$ \\
\hline
\end{tabular}

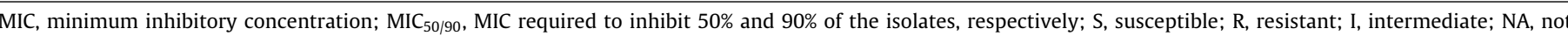
applicable (no breakpoint defined).

a Oral form (cefuroxime axetil).

b Not recommended for clinical use but tested here for epidemiological purposes.

category of EUCAST (no breakpoint set for CLSI). We examined the occurrence of efflux for ciprofloxacin by addition of reserpine. As illustrated in Fig. 3, there was a shift of the whole population towards lower MICs, with $38 \%$ and $35 \%$ of the isolates showing a 1 or $\geq 2 \log _{2}$ dilution changes, respectively. Lastly, the cumulative MIC distributions of telithromycin and solithromycin were very similar, with few (EUCAST) or no isolate (CLSI) categorised as resistant (breakpoints for solithromycin have not yet been set).

We then examined the correlation between the severity of disease and resistance of the isolates to amoxicillin and cefuroxime by stratifying patients by low ( 1 or 2 ) and high ( 3 or 4) GOLD scores, respectively, and performing a recursive partitioning analysis versus the MICs of their isolates. Whilst this allowed determination of a best MIC split value at $4 \mathrm{mg} / \mathrm{L}$ for amoxicillin and at $1 \mathrm{mg} / \mathrm{L}$ for cefuroxime, this was not statistically significant (LogWorth values $=0.18$ and 0.17 , respectively, corresponding to $P$-values of 0.66 and 0.68$)$. This was further confirmed by $2 \times 2$ contingency table analysis ( $P$-values of 0.18 and 0.31 ).

Fig. 4 shows the susceptibilities of the strains grouped by ST/SG for each of the antibiotics tested in Fig. 2 and ranked by their mean MIC value (from highest to lowest) with the corresponding EUCAST and CLSI intermediate susceptibility zones. Although the ranking of STs/SGs varied between antibiotics, global trends emerged with ST14, ST19A, SG9, SG29 and SG15 having the highest mean MICs for $\beta$-lactams, ST19A, SG9, ST14, SG19 and SG 33 for macrolides, ST14, ST19A, SG19, SG9 and SG17 for both ketolides, and ST19A, SG33, ST4, ST5 and SG15 for moxifloxacin and levofloxacin, respectively. All ST19A isolates had a MIC above the EUCAST resistance breakpoint for amoxicillin, cefuroxime, clarithromycin, azithromycin, moxifloxacin and levofloxacin. Conversely, SG7 and ST8 isolates were fully susceptible to all antibiotics (see Supplementary Table S1 for a ranking of all isolates stratified by ST/SG, MICs and resistance pattern).

\subsection{Biofilm production in relation to pneumococcal susceptibility} to antibiotics (minimum inhibitory concentrations and occurrence of efflux)

No significant correlation (one-way ANOVA with Tukey's posttest) was seen between biofilm production (crystal violet staining) and antimicrobial susceptibility (MIC) for each of the antibiotics tested (see data in Supplementary Fig. S3). Likewise, there was 


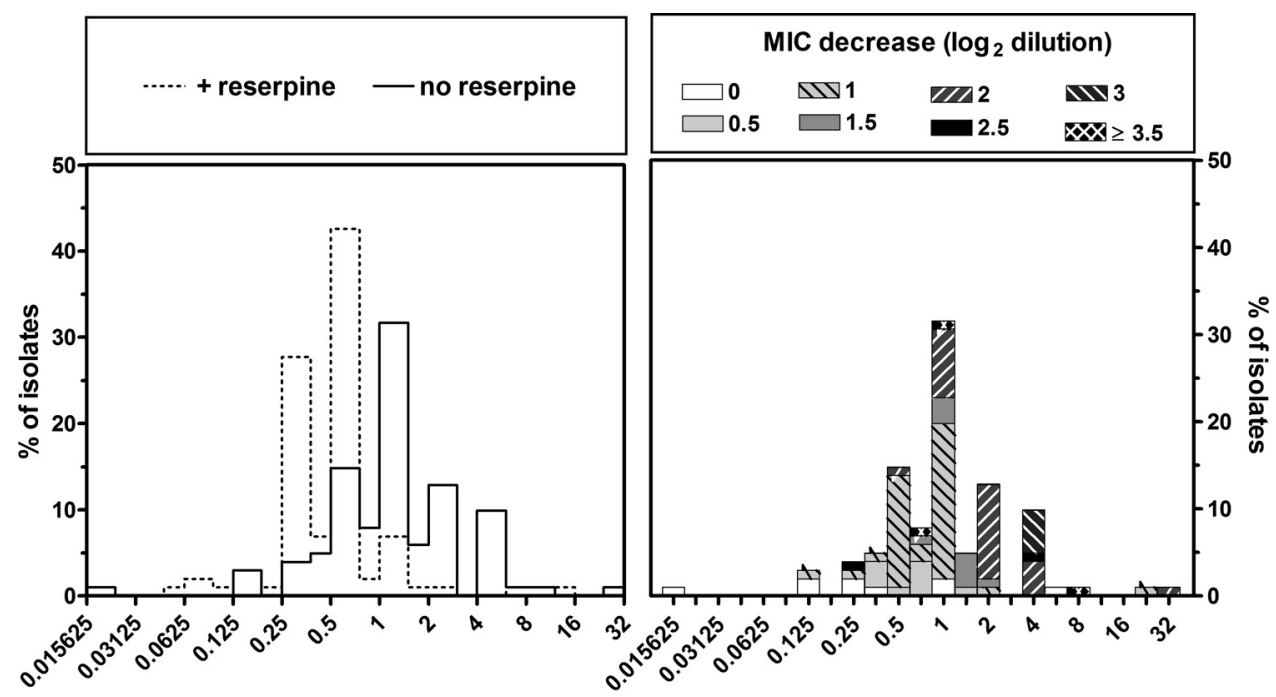

ciprofloxacin minimum inhibitory concentrations (mg/L)

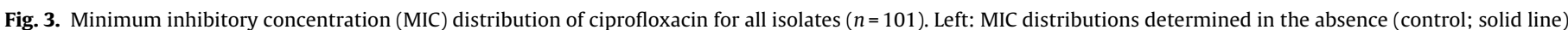

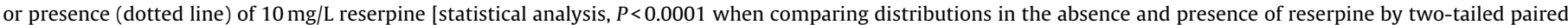

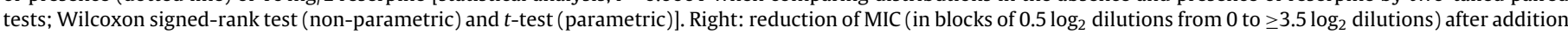
of $10 \mathrm{mg} / \mathrm{L}$ reserpine and plotted as a function of the MIC distribution of the isolates in the absence of reserpine.
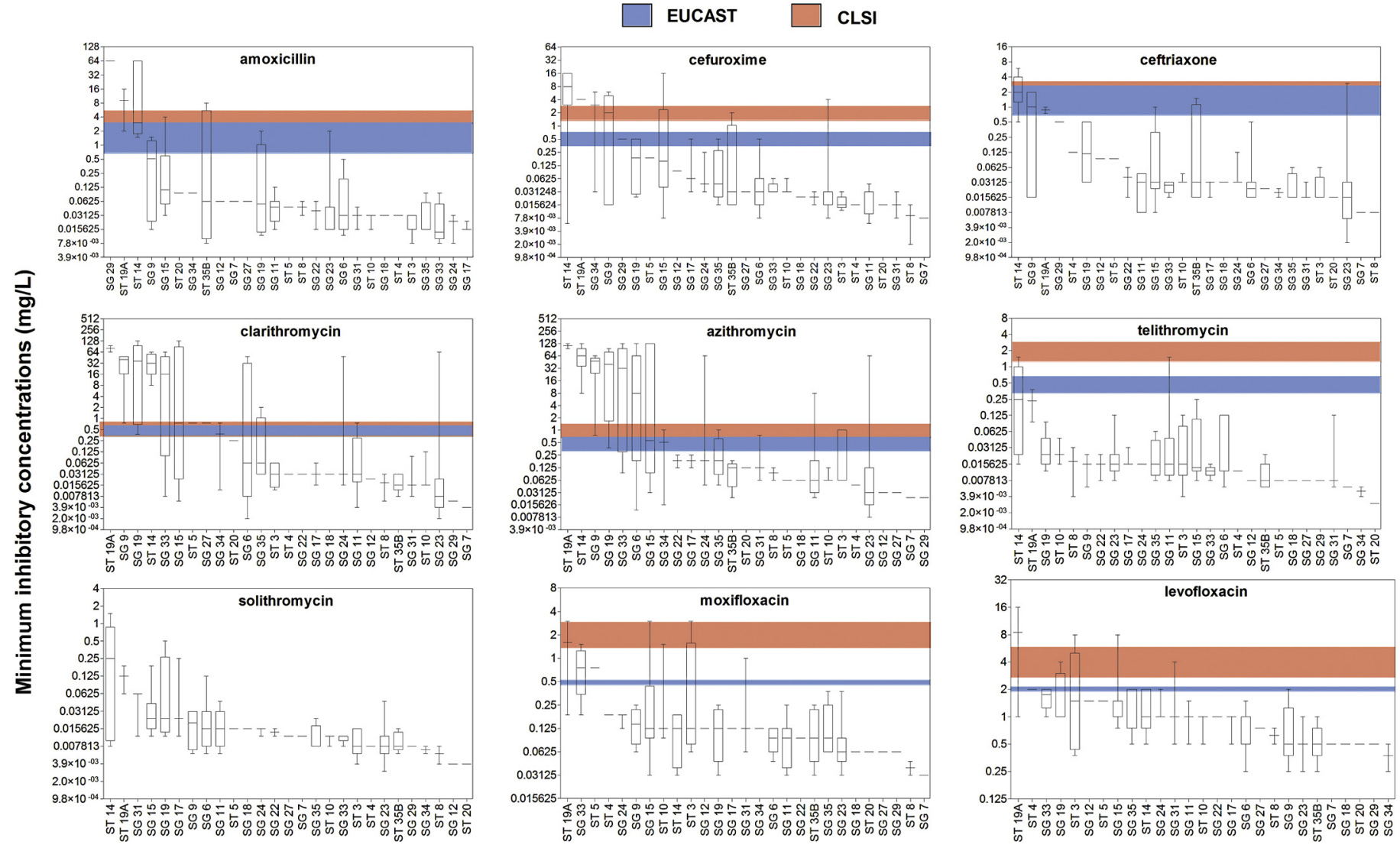

Serotypes (ST) / Serogroups (SG)

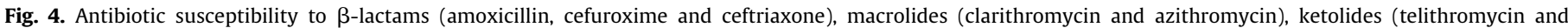

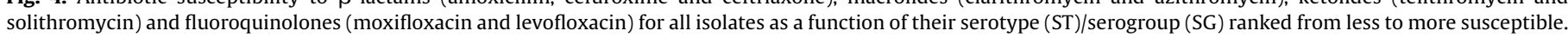

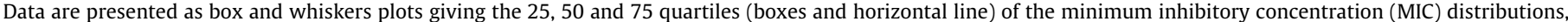

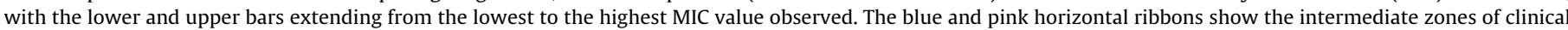

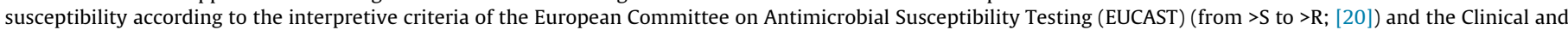

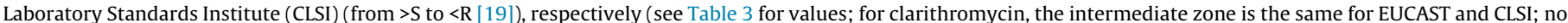

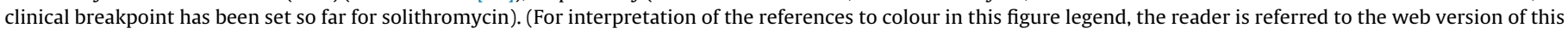
article.) 


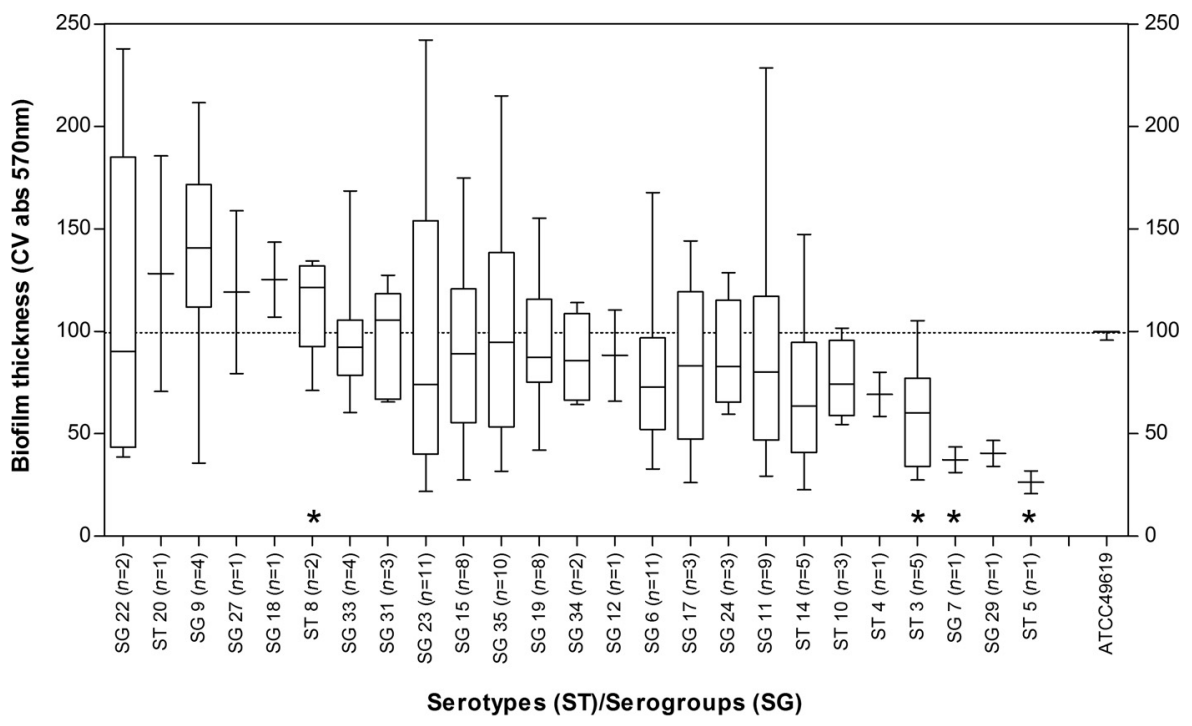

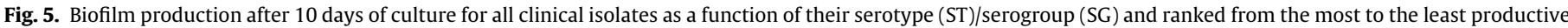

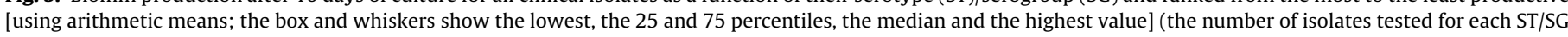

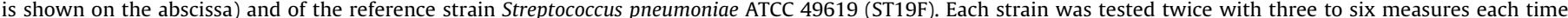

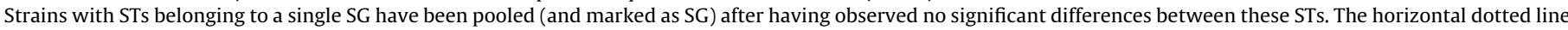

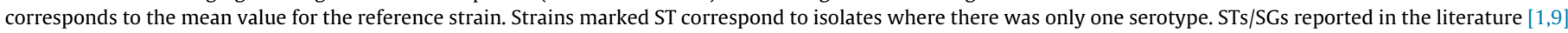
as causing acute infections are marked with an asterisk. CV, crystal violet.

no statistically significant correlation (unpaired $t$-test, Welch corrected) between biofilm production and expression of efflux for macrolides or ciprofloxacin (see data in Supplementary Fig. S4).

\subsection{Characterisation of biofilm formation in relation to pneumococcal serotype/serogroup}

Fig. 5 shows the amount of biomass observed at Day 10 for the reference strain S. pneumoniae ATCC 49619 (ST19F) and for the clinical isolates ranked by inverse amount of production and regrouped by ST/SG. Globally, all isolates, except SG7, SG29 and ST5, produced biofilm in a similar fashion to the reference strains ATCC 49619, with SG22, ST20, SG9, SG27, SG18 and ST8 being the most productive (SG9 and SG22 have been previously reported to be associated with chronic infections [1,9]). Conversely, SG7, SG29 and ST5 were the lowest producers in this collection, and these have been reported as poor producers with ST5 and SG7 claimed to be associated with acute infections [9].

\section{Discussion}

To the best of our knowledge, the present study is one of the first examining in a systematic fashion and correlating the STs/SGs, the resistance pattern and in vitro biofilm formation ability of $S$. pneumoniae isolates collected from COPD patients with a confirmed diagnosis of AECB. The number of patients and corresponding microbiological samples were limited due to the design of the study, which implied access to the medical history of the patients on the one hand, and the low rate of successful isolation of $S$. pneumoniae in this patient population on the other hand.

Within these limits, we first confirm and strengthen the close link existing between the severity of COPD and cardiovascular and diabetes pathologies already described in the literature [2,24]. A decreased ability to breathe reduces mobility, thereby favouring a sedentary lifestyle and weight gain. We next confirm that $\beta$ lactams, levofloxacin and moxifloxacin maintain useful activity against $S$. pneumoniae isolates from this population, although to a lesser extent than what we saw in a previous study for isolates obtained in Belgium from patients suffering from CAP during the 2006-2009 period [14]. Whilst the two patient populations cannot be directly compared, they nevertheless originate from the same small geographical area, suggesting that we deal, at least partially, with distinct bacterial populations. The lower susceptibility of isolates obtained from COPD patients probably reflects the large and prolonged use of antibiotics in this population before eventually reporting to the hospital (most patients suffering from CAP and included in our previous study had not received any antibiotic when enrolled [14]). Our findings, therefore, call for caution against the non-documented use of $\beta$-lactams [especially cefuroxime (given orally as cefuroxime axetil)] in COPD patients. For macrolides, the situation is even more critical as resistance patterns are appalling. Telithromycin, approved in Europe for the treatment of infections caused by $\beta$-lactam- and macrolide-resistant strains, maintains a very high level of activity, probably because of its very low use in Belgium owing to its non-inclusion as a recommended antibiotic for the treatment of AECB in local guidelines [22] (solithromycin is still an investigational drug). Of note is the larger prevalence of efflux for ciprofloxacin, especially if considering the proportion of isolates where a MIC change of $\geq 2 \log _{2}$ dilutions could be observed upon addition of reserpine. Whilst moxifloxacin and levofloxacin were not significantly affected, we know from previous studies that efflux of ciprofloxacin can herald similar changes in MICs for other fluoroquinolones proposed for the treatment of respiratory tract infections such as gemifloxacin and garenoxacin [25].

Analysis of the susceptibility pattern in relation to their ST/SG shows that some of them (ST19A, ST14, SG9 and SG9) have a high level of resistance to $\beta$-lactams and macrolides [and decreased susceptibility to ketolides (ST19A and ST14 only)] but not to moxifloxacin (except for ST19A). This is largely akin to our previous findings for isolates from patients suffering from CAP [14] as well as data from other countries in Europe [26] and the Far East $[27,28]$. Thus, determination of the prevalent STs/SGs in patients may help in fine-tuning therapy by avoiding the use of antibiotics known to be poorly effective. Determination of the nucleotide sequence of the $\alpha$-helical region of the pneumococcal surface protein (PspA), also proposed as a predictor of multiresistance 
[28], could not be examined in the context of the present study.

Turning our attention now to biofilm production, we see that most isolates obtained in this study were high producers (similar to the reference strain ATCC 49619 [ST19F] also known as a high producer $[1,18])$. In the present study, careful attention was paid to obtain data as reproducible as possible for biofilm production. Thus, by and large, this production appears to be a property shared by most isolates from COPD patients, suggesting that previous reports linking poor biofilm production by some of the strains studied here to more acute infections may need revisiting [9]. Conversely, we confirm that strains previously reported to be largely associated with acute infections, such as ST8 and ST3 [1], are indeed poor biofilm producers.

Lastly, we show no correlation between biofilm formation and intrinsic susceptibility or expression of macrolide or ciprofloxacin efflux in the isolates studied. This could explain why the determination of susceptibility by the reference methods (which use planktonic cells) may fail to truly predict the clinical outcome. Eradication of bacteria from biofilms, indeed, requires antibiotic concentrations to be maintained at values much larger than the breakpoint, especially if considering $\beta$-lactams and macrolides against mature biofilms [18]. The lack of correlation between biofilm production and ciprofloxacin efflux, which is in contrast with what is observed in Gram-negative bacteria, probably relates to differences in quorum-sensing signalling pathways and the secretion of the corresponding mediators [13,29,30].

Funding: PMT has received research grants from Fonds de la Recherche Scientifique [grants 3.4530.12 and T.0134.13] and the Interuniversity Attraction Poles Programme initiated by the Belgian Science Policy Office [program IAP P7/28] and grants-in-aid from Cempra Pharmaceuticals and Bayer AG.

Competing interests: NMV is boursière of the Belgian Fonds pour la Recherche dans l'Industrie et l'Agriculture (FRIA); FVB is Maître de Recherches of the Belgian Fonds de la Recherche Scientifique (F.R.S.-FNRS); PMT and FVB have received research grants from Fonds de la Recherche Scientifique [grants 3.4530 .12 and T.0134.13] and the Interuniversity Attraction Poles Programme initiated by the Belgian Science Policy Office [program IAP P7/28], grants-in-aid from Cempra Pharmaceuticals and Bayer AG, and consultancy fees from Bayer AG. All other authors declare no competing interests.

Ethical approval: The entire study protocol was submitted and approved by the Commission d'éthique facultaire of the Université catholique de Louvain (Brussels, Belgium) [unique Belgian no. 40320109783]. The ethical committee of the participating hospitals also gave their approval for the specific studies and access to medical files in the corresponding institutions.

\section{Appendix A. Supplementary data}

Supplementary data associated with this article can be found, in the online version, at http://dx.doi.org/10.1016/j.ijantimicag. 2014.05.016.

\section{References}

[1] Domenech A, Ardanuy C, Pallares R, Grau I, Santos S, De la Campa AG, et al Some pneumococcal serotypes are more frequently associated with relapses of acute exacerbations in COPD patients. PLOS ONE 2013;8:e59027.

[2] Sin DD, Anthonisen NR, Soriano JB, Agusti AG. Mortality in COPD: role of comorbidities. Eur Respir J 2006:28:1245-57.

[3] Anthonisen NR, Manfreda J, Warren CP, Hershfield ES, Harding GK, Nelson NA. Antibiotic therapy in exacerbations of chronic obstructive pulmonary disease. Ann Intern Med 1987;106:196-204.

[4] Eller J, Ede A, Schaberg T, Niederman MS, Mauch H, Lode H. Infective exacerbations of chronic bronchitis: relation between bacteriologic etiology and lung function. Chest 1998;113:1542-8.
[5] Bronzwaer SL, Cars O, Buchholz U, Molstad S, Goettsch W, Veldhuijzen IK, et al. A European study on the relationship between antimicrobial use and antimicrobial resistance. Emerg Infect Dis 2002;8:278-82.

[6] Van Bambeke F, Reinert RR, Appelbaum PC, Tulkens PM, Peetermans WE. Multidrug-resistant Streptococcus pneumoniae infections: current and future therapeutic options. Drugs 2007;67:2355-82.

[7] Costerton JW, Stewart PS, Greenberg EP. Bacterial biofilms: a common cause of persistent infections. Science 1999;284:1318-22.

[8] Moscoso M, García E, López R. Pneumococcal biofilms. Int Microbiol 2009;12:77-85.

[9] Dagan R, Leibovitz E, Greenberg D, Bakaletz L, Givon-Lavi N. Mixed pneumococcal-nontypeable Haemophilus influenzae otitis media is a distinct clinical entity with unique epidemiologic characteristics and pneumococcal serotype distribution. J Infect Dis 2013;208:1152-60.

[10] Marks LR, Parameswaran GI, Hakansson AP. Pneumococcal interactions with epithelial cells are crucial for optimal biofilm formation and colonization in vitro and in vivo. Infect Immun 2012;80:2744-60.

[11] Brueggemann AB, Griffiths DT, Meats E, Peto T, Crook DW, Spratt BG. Clonal relationships between invasive and carriage Streptococcus pneumoniae and serotype- and clone-specific differences in invasive disease potential. J Infect Dis 2003;187:1424-32.

[12] Li Y, Weinberger DM, Thompson CM, Trzcinski K, Lipsitch M. Surface charge of Streptococcus pneumoniae predicts serotype distribution. Infect Immun 2013;81:4519-24

[13] Sivaneson M, Mikkelsen H, Ventre I, Bordi C, Filloux A. Two-component regulatory systems in Pseudomonas aeruginosa: an intricate network mediating fimbrial and efflux pump gene expression. Mol Microbiol 2011;79:1353-66.

[14] Lismond A, Carbonnelle S, Verhaegen J, Schatt P, De Bel A, Jordens P, et al Antimicrobial susceptibility of Streptococcus pneumoniae isolates from vaccinated and non-vaccinated patients with a clinically confirmed diagnosis of community-acquired pneumonia in Belgium. Int J Antimicrob Agents 2012;39:208-16.

[15] Global Initiative for Chronic Obstructive Lung Disease. Pocket guide to COPD diagnosis, management, and prevention. A guide for health care professionals; 2013. http://www.goldcopd.org/uploads/users/files/GOLD Pocket_2013_Mar27.pdf [accessed 2013].

[16] Lubin JH, Caporaso N, Wichmann HE, Schaffrath-Rosario A, Alavanja MC. Cigarette smoking and lung cancer: modeling effect modification of total exposure and intensity. Epidemiology 2007;18:639-48.

[17] Flamaing J, Verhaegen J, Vandeven J, Verbiest N, Peetermans WE. Pneumococcal bacteraemia in Belgium (1994-2004): the pre-conjugate vaccine era J Antimicrob Chemother 2008:61:143-9.

[18] Vandevelde NM, Tulkens PM, Van Bambeke F. Antibiotic activity against naive and induced Streptococcus pneumoniae biofilms in an in vitro pharmacodynamic model. Antimicrob Agents Chemother 2014;58:1348-58.

[19] Clinical and Laboratory Standards Institute. Performance standards for antimicrobial susceptibility testing; twenty-third informational supplement Document M100-S23. Wayne, PA: CLSI; 2013.

[20] European Committee on Antimicrobial Susceptibility Testing. Breakpoint tables for interpretation of MICs and zone diameters. Version 4.0, valid from 01.01.2014. http://www.eucast.org [accessed 19.06.14].

[21] Almeida ST, de Lencastre H, Sa-Leao R. Epidemiology and population structure of serotypes 1, 5 and 7F carried by children in Portugal from 1996-2010 before introduction of the 10-valent and 13-valent pneumococcal conjugate vaccines. PLOS ONE 2013;8:e75442.

[22] BAPCOC. Guide belge des traitements anti-infectieux en pratique ambulatoire. édition 2008. http://www.health.belgium.be/eportal/Myhealth/ Properuse/Antibiotics $/ 15616531$ _FR?ie2Term=BAPCOC\&ie2section=83 [accessed 30.06.14].

[23] Farrell DJ, Sader HS, Castanheira M, Biedenbach DJ, Rhomberg PR, Jones RN. Antimicrobial characterisation of CEM-101 activity against respiratory tract pathogens, including multidrug-resistant pneumococcal serogroup 19A isolates. Int J Antimicrob Agents 2010;35:537-43.

[24] Lindberg A, Larsson LG, Ronmark E, Lundback B. Co-morbidity in mild-tomoderate COPD: comparison to normal and restrictive lung function. COPD $2011 ; 8: 421-8$

[25] Lismond A, Carbonnelle S, Tulkens PM, Van Bambeke F. Efflux of novel quinolones in contemporary Streptococcus pneumoniae isolates from community-acquired pneumonia. J Antimicrob Chemother 2011;66: 948-51.

[26] Gajic I, Mijac V, Ranin L, Andjelkovic D, Radicevic M, Opavski N. Invasive isolates of Streptococcus pneumoniae in Serbia: antimicrobial susceptibility and serotypes. Srp Arh Celok Lek 2013;141:48-53 [in Serbian].

[27] Liu C, Xiong X, Xu W, Sun J, Wang L, Li J. Serotypes and patterns of antibiotic resistance in strains causing invasive pneumococcal disease in children less than 5 years of age. PLOS ONE 2013;8:e54254.

[28] Hotomi M, Togawa A, Kono M, Ikeda Y, Takei S, Hollingshead SK, et al. PspA family distribution, antimicrobial resistance and serotype of Streptococcus pneumoniae isolated from upper respiratory tract infections in Japan. PLOS ONE 2013:8:e58124.

[29] Vallet I, Olson JW, Lory S, Lazdunski A, Filloux A. The chaperone/usher pathways of Pseudomonas aeruginosa: identification of fimbrial gene clusters (cup) and their involvement in biofilm formation. Proc Natl Acad Sci USA 2001:98:6911-6.

[30] Li YH, Tian X. Quorum sensing and bacterial social interactions in biofilms. Sensors (Basel) 2012;12:2519-38. 


\section{Supplementary Table S1}

Isolate ranking for each serotype (ST)/serogroup (SG) as a function of their minimum inhibitory concentration (MIC). STs/SGs are ranked from the least susceptible (small ranking value) to the most susceptible (high ranking value)

\begin{tabular}{|c|c|c|c|c|c|c|c|}
\hline \multicolumn{2}{|c|}{$\beta$-Lactams ${ }^{a}$} & \multicolumn{2}{|c|}{ Macrolides ${ }^{b}$} & \multicolumn{2}{|c|}{ Ketolides $^{c}$} & \multicolumn{2}{|c|}{ Fluoroquinolones $^{d}$} \\
\hline ST/SG & Ranking $^{\mathrm{e}}$ & ST/SG & Ranking $^{\mathrm{e}}$ & ST/SG & Ranking $^{\mathrm{e}}$ & ST/SG & Ranking $^{\mathrm{e}}$ \\
\hline ST 14 & 5 & ST 19A & 2 & ST 14 & 2 & ST 19A & 2 \\
\hline ST 19A & 7 & SG 9 & 5 & ST 19A & 4 & SG 33 & 5 \\
\hline SG 9 & 10 & ST 14 & 6 & SG 19 & 8 & ST 4 & 6 \\
\hline SG 29 & 10 & SG 19 & 7 & SG 9 & 13 & ST 5 & 10 \\
\hline SG 15 & 23 & SG 33 & 10 & SG 17 & 15 & SG 15 & 15 \\
\hline SG 19 & 23 & SG 15 & 12 & SG 15 & 18 & ST 3 & 15 \\
\hline SG 12 & 24 & SG 34 & 16 & SG 22 & 20 & SG 19 & 16 \\
\hline ST 5 & 28 & SG 6 & 17 & SG 11 & 21 & SG 24 & 16 \\
\hline SG 34 & 30 & ST 20 & 24 & ST 10 & 21 & SG 12 & 17 \\
\hline ST 35B & 34 & ST 5 & 24 & SG 24 & 22 & ST 14 & 19 \\
\hline SG 27 & 43 & SG 22 & 24 & SG 6 & 24 & ST 10 & 22 \\
\hline SG 22 & 43 & SG 35 & 24 & SG 31 & 27 & SG 9 & 26 \\
\hline SG 11 & 45 & SG 17 & 26 & SG 35 & 27 & SG 31 & 26 \\
\hline ST 10 & 49 & SG 24 & 29 & SG 23 & 29 & SG 35 & 29 \\
\hline SG 6 & 50 & SG 27 & 33 & ST 5 & 30 & SG 17 & 29 \\
\hline SG 17 & 51 & ST 3 & 34 & ST 8 & 30 & SG 11 & 30 \\
\hline ST 4 & 52 & ST 35B & 35 & SG 18 & 32 & SG 22 & 33 \\
\hline SG 33 & 52 & SG 18 & 35 & ST 3 & 32 & SG 6 & 33 \\
\hline ST 20 & 53 & ST 4 & 36 & SG 33 & 33 & ST 35B & 41 \\
\hline SG 24 & 53 & ST 8 & 37 & SG 27 & 36 & SG 34 & 42 \\
\hline SG 18 & 54 & SG 11 & 38 & ST 4 & 37 & SG 27 & 42 \\
\hline SG 35 & 56 & SG 31 & 38 & SG 7 & 40 & SG 23 & 42 \\
\hline SG 23 & 61 & SG 12 & 44 & ST 35B & 41 & ST 8 & 45 \\
\hline SG 7 & 63 & ST 10 & 44 & SG 12 & 44 & SG 18 & 46 \\
\hline SG 31 & 65 & SG 23 & 48 & SG 29 & 46 & ST 20 & 48 \\
\hline ST 3 & 66 & SG 29 & 53 & SG 34 & 50 & SG 7 & 50 \\
\hline
\end{tabular}




\section{\begin{tabular}{llllllll}
\hline ST 8 & 68 & SG 7 & 53 & ST 20 & 54 & SG 29 & 51 \\
\hline
\end{tabular} \\ ${ }^{a}$ Amoxicillin, cefuroxime and ceftriaxone. \\ ${ }^{\mathrm{b}}$ Clarithromycin and azithromycin. \\ ${ }^{\mathrm{c}}$ Telithromycin and solithromycin. \\ ${ }^{\mathrm{d}}$ Moxifloxacin and levofloxacin. \\ ${ }^{\mathrm{e}}$ Ranking values were calculated by adding, for drugs belonging to the same antibiotic class, the numbers of ranking positions (from 1 to 27 ) of each ST/SG, following their classification in Fig. 3 (from the least to the most susceptible). The five most susceptible and resistant STs/SGs are marked in colour. Similar colours indicate similarities between antibiotic classes.}


Supplementary Fig. S1. Distribution of serogroups with an incidence $>7.5 \%$ in the whole population $(n=101)$ across the provinces where patients were living (provinces with no patients are labelled in grey).

Supplementary Fig. S2. Minimum inhibitory concentration (MIC) distributions (cumulative percentages) of the macrolide and fluoroquinolone markers of efflux, respectively, for 101 non-duplicate Streptococcus pneumoniae isolates from chronic obstructive pulmonary disease patients: clindamycin versus clarithromycin (left panel) and ciprofloxacin versus ciprofloxacin + reserpine (R) (right panel). Three horizontal dotted lines are drawn at values corresponding to the $\mathrm{MIC}_{50}, \mathrm{MIC}_{90}$ and $\mathrm{MIC}_{100}$ (MICs required to inhibit 50\%, $90 \%$ and $100 \%$ of the isolates, respectively).

Supplementary Fig. S3. Box and whisker plots representing biofilm production after 10 days of culture for all isolates as a function of their minimum inhibitory concentration (MIC) in broth for three $\beta$-lactams (amoxicillin, cefuroxime and ceftriaxone), two macrolides (clarithromycin and azithromycin), two ketolides (telithromycin and solithromycin) and two fluoroquinolones (moxifloxacin and levofloxacin). Data are presented as box and whiskers plots giving the 25,50 and 75 quartiles (boxes and horizontal line) and extending from 0 to $100 \%$ of the isolates. No significant correlation was seen between MIC and biofilm thickness [one-way analysis of variance (ANOVA) with or without Tukey's post-test]. CV, crystal violet.

Supplementary Fig. S4. Distribution of isolate biofilm production as a function of phenotypic efflux. Comparison of biofilm production after 10 days of culture for strains resistant to both clarithromycin and azithromycin and to ciprofloxacin using 
European Committee on Antimicrobial Susceptibility Testing (EUCAST) interpretive criteria (Breakpoint tables for interpretation of MICs and zone diameters. Version 4.0; http://www.eucast.org [accessed 2014]) and grouped according to the absence (open symbols) or presence (closed symbols) of efflux as detected for clarithromycin and azithromycin by dissociation of susceptibilities with clindamycin, and for ciprofloxacin by a two-fold decrease in minimum inhibitory concentrations upon addition of reserpine (10 mg/L). No correlation between efflux and biofilm thickness was seen (unpaired $t$-test, with or without Welch correction). CV, crystal violet. 


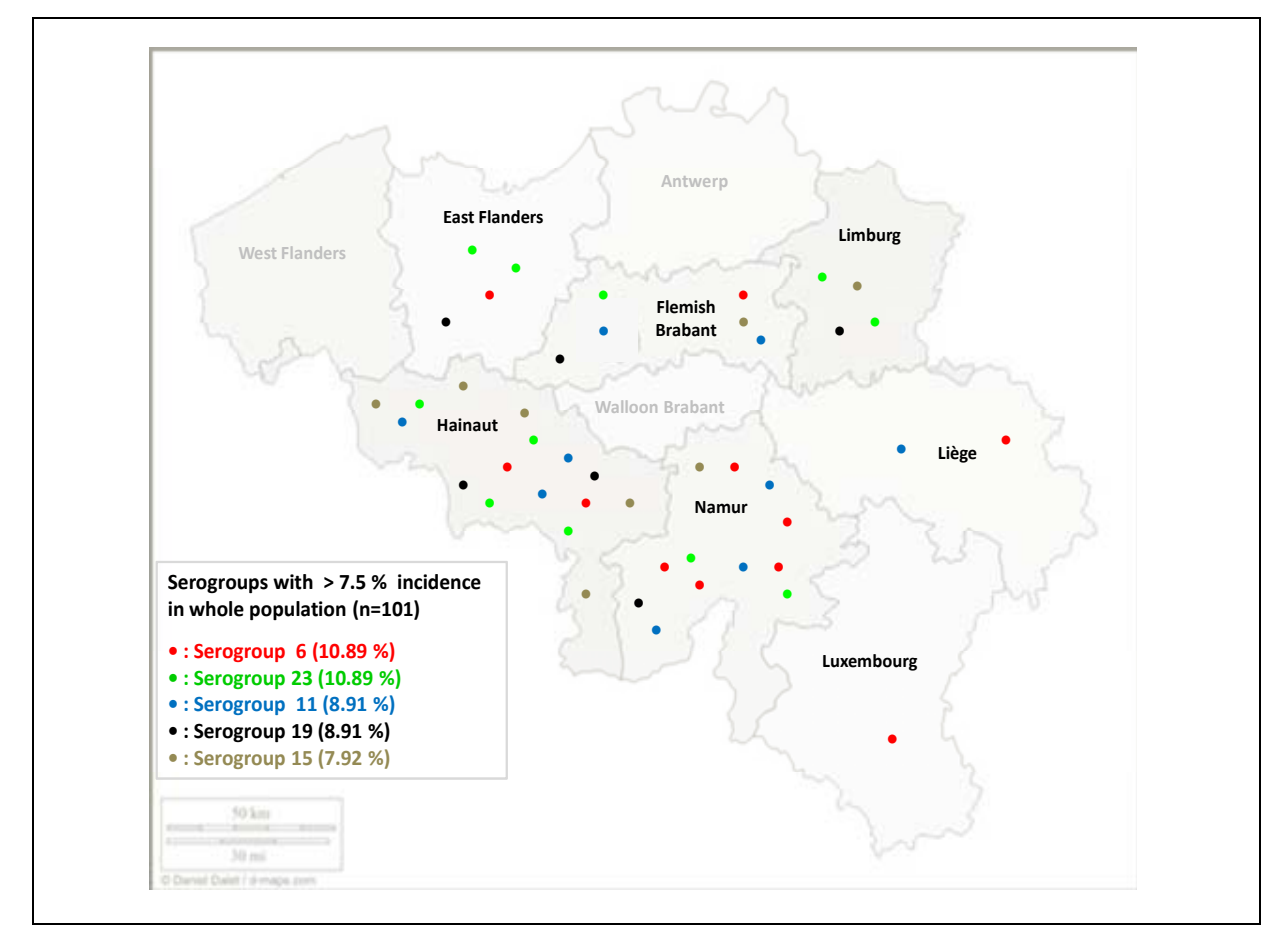



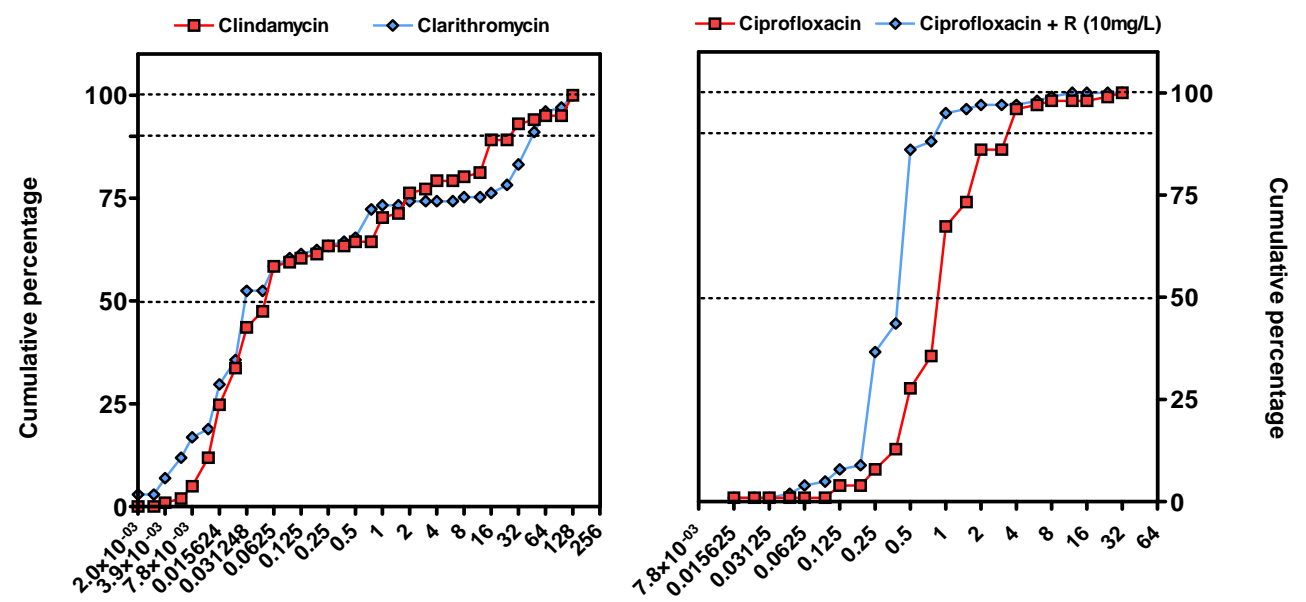

Minimal inhibitory concentrations (mg/L) 

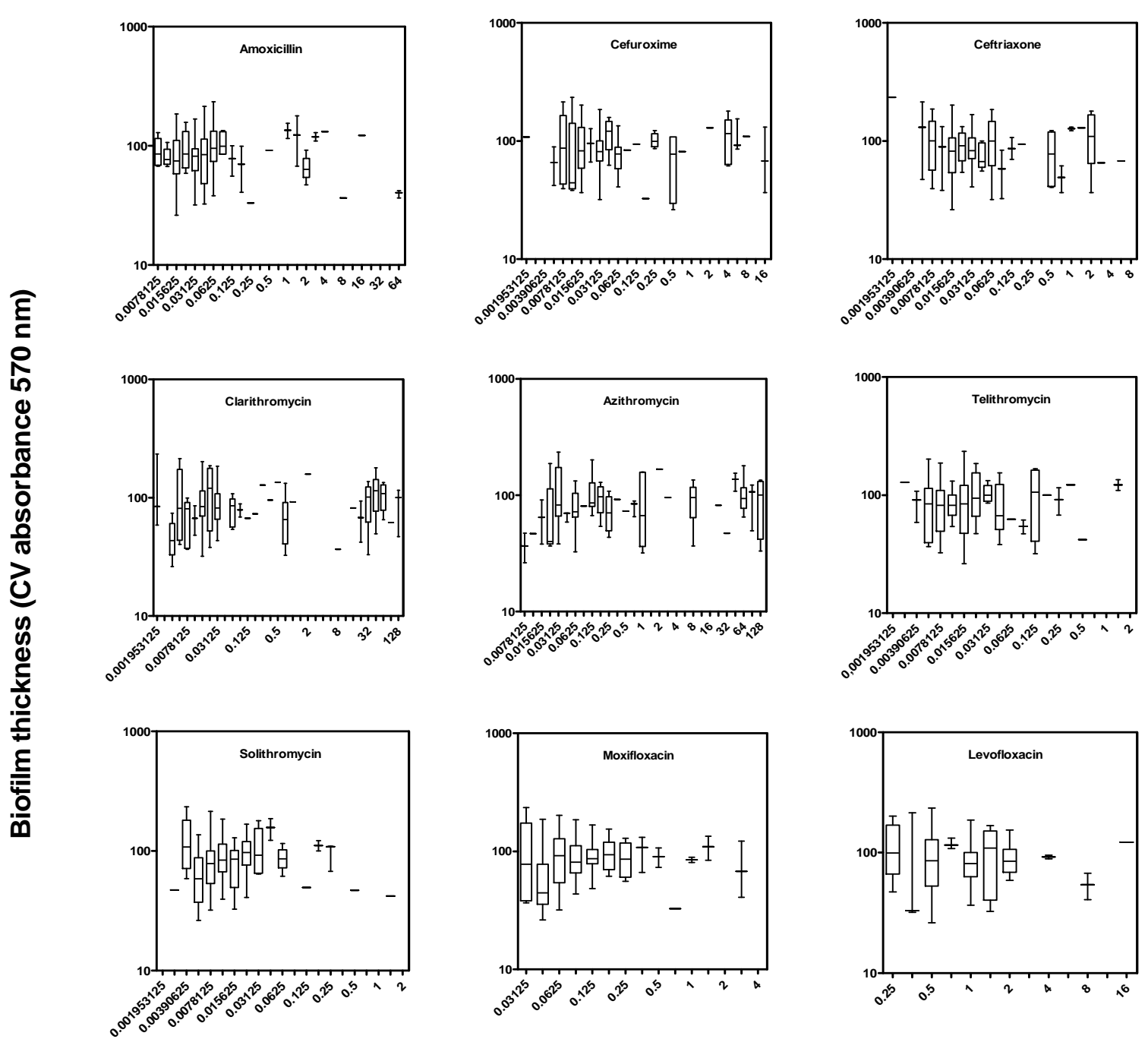

Minimal inhibitory concentrations (mg/L) 


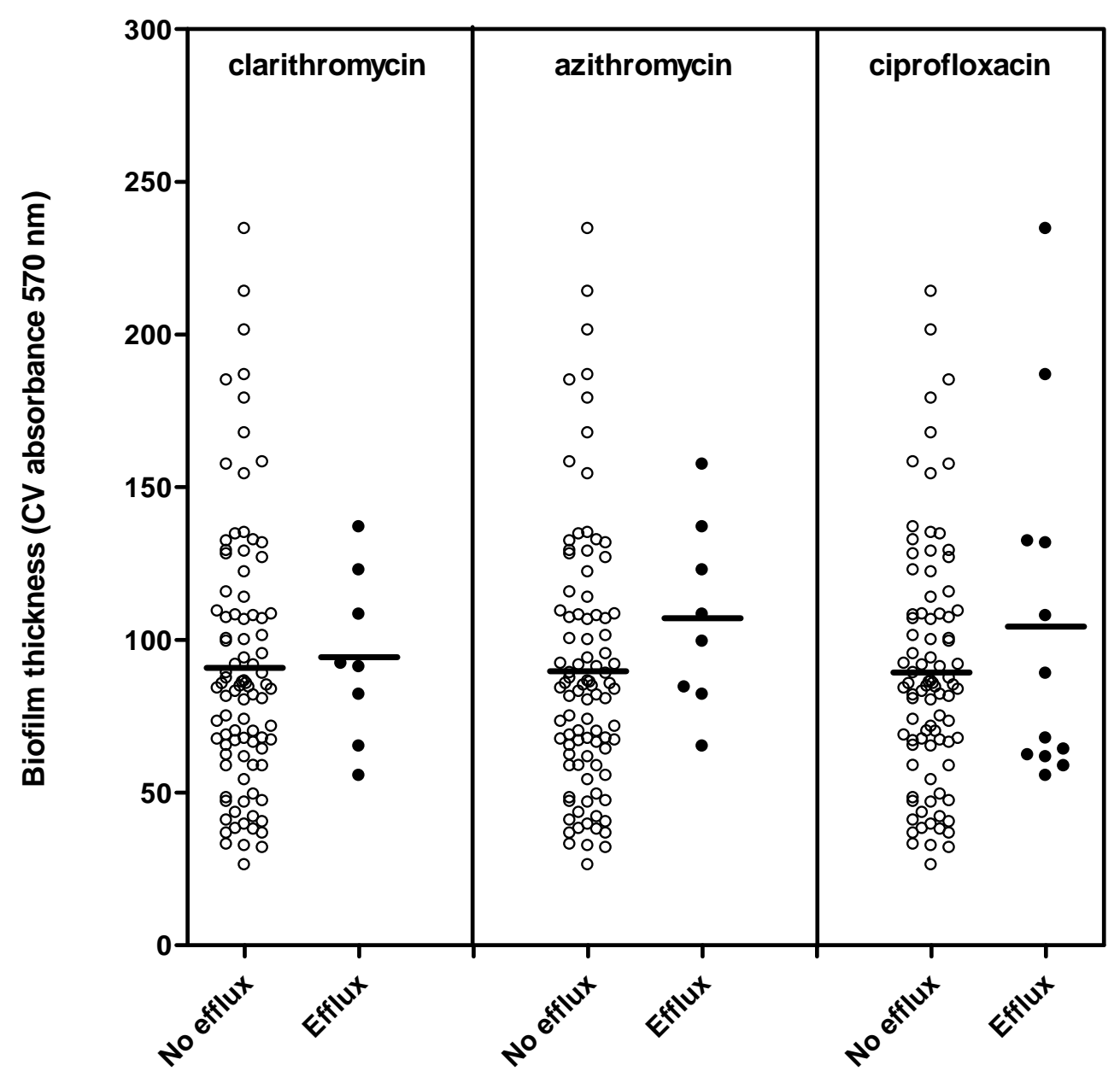

